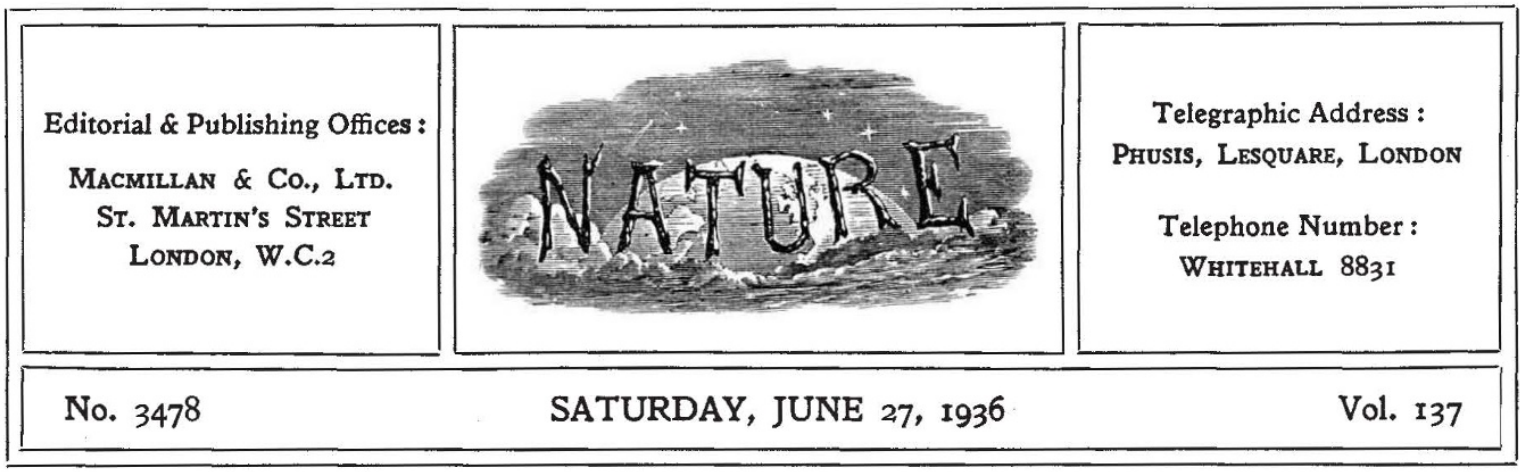

\title{
The Centenary of the University of London
}

D URING the week June 29-July 3 will be celebrated the centenary of the University of London. The granting of its first Charter in 1836 by H.M. William IV was an important landmark not only in the history of education but also in the history of science itself. It must be remembered that, in the early nineteenth century, England had only the two Universities of Oxford and Cambridge, and these "kept the noiseless tenour of their way", steeped in the traditional policy of medieval times and paying little attention to the new sciences which were then arousing the interest and enthusiasm of many men whose names were destined to be world-famous. Limited in curriculum for the most part to the study of mathematics and the classical languages, restricted in membership to those who subscribed to the doctrines of the Established Church, the older universities seemed to stand for all that was conservative and reactionary. The movement for a new university was one aspect of the general attack on privilege which resulted in the Reform Act of 1832 and the social and legal reforms associated with the names of Bentham and Brougham.

The establishment of the 'godless' University College at Gower Street in 1827 was regarded not only with derision but also with alarm. Many public men were seriously concerned at the growth of the new 'liberal' spirit, and grave doubts were expressed in Parliament, in the Press and elsewhere as to the desirability of encouraging such an institution. The struggle for recognition was long and bitter, but eventually the Government was forced to give way, and the University of London came into being. Even then, it was only a compromise : the new University was constituted solely as an examining and degree-giving body, and the teaching was entrusted to the two Colleges, University and King's, which were already in existence. The despised infant, unwanted and debarred from its full rights, nevertheless thrived well, and soon began to show a lively interest in the new sciences. This was no doubt due to the composition of the Governing Body, which included some of the most eminent men of the Victorian age. The Charter of 1836 nominated as fellows and members of the Senate no less than fifteen fellows of the Royal Society, among whom were Airy-the Astronomer Royal-Neil Arnott, Francis Beaufort, John Shaw Lefevre, Peter Mark Roget, Nassau Senior. Michael Faraday, especially, played a prominent part in the affairs of the University for nearly thirty years. There was no lack of such men to carry on their policy : later there occur in the minutes of the Senate the names of Hooker, Huxley, Lister, Paget, Sharpey, Foster and Ray Lankester.

Under the guidance of these eminent men, the examination curriculum was established on a broad and truly liberal basis : and a high standard was set and maintained. Recognition was accorded to subjects previously either neglected or com. pletely ignored, such as English, history, modern languages, chemistry. The pioneers justified the inclusion of these, not only as subjects worthy of study in themselves but also as providing a training for the mind equally as beneficial as that claimed for the more ancient studies. What Arnold of Rugby achieved for the Faculty of Arts, Faraday and others did for the Faculty of Science. A momentous step was taken when in 1860 degrees in science were instituted for the first time in England, and academic recognition thus obtained 
for the scientific teaching which was being carried on in London and the provinces.

In medicine, too, great emphasis was from the beginning laid upon the necessity of adequate study of the pre-clinical sciences, and this did much to raise the standard of medical education-a sorely needed reform. Doctors of science were required to present a thesis which should stand the regulation test of the Royal Society and be judged to contain to some extent "an addition to knowledge". The graduates themselves took a keen interest in matters of educational policy. They procured the recognition of the London medical degree as a licence to practise ; and a resolution of Convocation in 1878 urged that encouragement should be given to the "cultivation of such higher and less usual branches of study as can be more conveniently or more efficiently taught by a central body". To the very extent of its power, the University fostered the advancement of science, but its influence was, from the nature of things, only indirect. It had indeed one research institute, the Brown Institution, founded in 1871, and the names of successive professor-superintendentsBurdon-Sanderson, Horsley and Sherrington-are an eloquent tribute to the pioneer nature of its work.

In the colleges and institutions from which the University drew its candidates were many other leaders of science. University College established the first chemical and engineering laboratories in England. Chairs were established in geology, botany and zoology : the School of Anatomy and Physiology was made famous by Sharpey and his pupils, Michael Foster and Burdon-Sanderson. At King's College, founded in 1829 as the Tory counterblast to the Whig institution in Gower Street, the professoriate included Sir Charles Lyell, Charles Wheatstone, Clerk Maxwell, and later Lister himself. The great group of institutions founded in 1851 at South Kensington (later to be known as the Imperial College) was a pioneer in the teaching of science and technology, and reveres the names of Huxley, Tyndall and Unwin. For about sixty years, the University performed its function as an examining body. Though limited in scope, its influence on the development of secondary education in England (through the famous matriculation examination) was profound. On higher education, also, its influence was no less widespread and lasting, for to many of the provincial university colleges London acted as a sort of foster mother ; and their students entered for the London examina- tions until they themselves became fully-fledged universities.

As the nineteenth century drew to a close, there came the growing realisation that neither the University nor the teaching institutions it served were getting the fullest benefit from the existing relationship. After much debate and the delibera. tions of two Royal Commissions, a new constitution was granted in 1900 . The University now took on all the functions of a teaching university. The existing institutions of university rank became Schools of the University, and then at last began the process of co-ordinating and unifying their vast resources. University and King's College, with their long and illustrious record of scientific achievement, were joined by the newly reorganised Imperial College, by the pioneer women's colleges such as Bedford and the London School of Medicine for Women, and by the medical schools attached to the great hospitals of the Metropolis. To these were later added several Schools devoted mainly to post-graduate study and research.

The last thirty years have seen an unprecedented advance in scientific knowledge and its practical application, and the University has had constantly to adjust itself to meet the growing demands upon it. New degrees and diplomas have been instituted, new subjects have been included in the curriculum. Chairs have been established in such diverse subjects as eugenics, aeronautics, social biology, chemical engineering, etc. The provision of scholarships and research funds and of spacious and well-equipped laboratories is the constant concern of the University and its Schools, which now possess some of the finest and most up-todate laboratories in Great Britain. By the development of such specialised institutions as the London School of Hygiene and Tropical Medicine and the British Postgraduate Medical School, London is rapidly becoming a centre for advanced teaching and research for Europe and the Empire.

Delegates from universities and learned societies throughout the world will assemble in London to take part in the official celebrations of the centenary. Those from the United States include Prof. G. D. Birkhoff, dean of the Faculty of Arts and Science at Harvard, Prof. L. P. Eisenhart from Princeton, Prof. W. G. Whitman, head of the Department of Chemical Engineering at the Massachusetts Institute of Technology, Prof. H. Bateman of the California Institute of Technology, and Dr. R. E. Swain, chairman of the School of Physical Sciences at Stanford University. Distinguished 
European men of science who are coming over include Dr. Jaroslav Heyrovský, who will represent the Charles University of Prague, the Bohemian Royal Society of Sciences and the Czech Academy of Sciences and Arts; Prof. Sem Saeland, Rector of the University of Oslo, who will represent also the Norwegian Academy of Sciences; Dr. Nils Svedelius, professor of botany in the University of Uppsala, and representative of the Royal Swedish Academy of Sciences and the Royal Society of Sciences, Uppsala; M. Jean Perrin, president, and M. Charles Fabry, of the Paris Academy of Sciences; Prof. P. Zeeman, Rector of the University of Amsterdam, and Dr. J. Huizinga, of the Royal Academy of Science, Amsterdam.

The celebrations include a special service at St. Paul's Cathedral, to be followed by a luncheon at the Guildhall given by the City Corporation. Evening receptions will be given by the Government and the London County Council. The Schools of the University will extend hospitality and be open to inspection by the University's guests. At a reception to be given by the University, honorary degrees will be conferred on a number of eminent men. The degree of doctor of science will be conferred on Sir William Bragg, president of the Royal Society, on Prof. Albert Einstein and Prof. Max Planck in recognition of their great contributions to physical science, and on Prof. Johan Hjort, professor of marine biology at the University of Oslo and an outstanding scientific representative of the Scandinavian peoples. Sir Joseph Larmor, the distinguished mathematician, will receive the degree of doctor of laws, and Mr. H. G. Wells, who is a former student of Imperial College and who has done so much to promote interest in science and the scientific spirit through the medium of his pen, will become a doctor of literature. In honouring these men by admission to its society, the University adds lustre to its already brilliant record of service and achievement in the cause of science and learning.

\section{The Work of William B. Hardy}

Collected Scientific Papers of Sir William Bate Hardy, Fellow of the Royal Society, Fellow of Gonville and Caius College, Cambridge

(Published under the auspices of the Colloid Committee of the Faraday Society.) Pp. xi +922 +15 plates. (Cambridge: At the University Press, 1936.) 63s. net.

IN a short preface Prof. Eric K. Rideal states I that this volume of collected papers is published under the auspices of the Colloid Committee of the Faraday Society, but omits to mention that the Committee undertook this task at his suggestion. Contributions to the cost have been made by the Dominion Governments of Australia, South Africa and New Zealand; the master and fellows of Gonville and Caius College ; the Royal Society and the Chemical, Biochemical, Physiological and Faraday Societies. The Cambridge University Press has produced the work in a style conforming to its usual high standard.

The contents of the volume fall into three very distinct groups: papers on physiological and histological subjects; papers on the fundamental problems of the colloidal state; and papers on the boundary state', that is, on the behaviour of liquids and solids at the interfaces between the two.
It is undoubtedly Hardy's work on colloids which has made his name familiar to the largest number of readers. The question of what led him to take up these researches is answered epigrammatically by the master of his college in a remark quoted in the preface: "Hardy once observed a cell divide under the microscope, and wondered why". If the elucidation of this process was his ultimate aim, the first steps towards it led him away from living matter. Dissatisfied with the prevailing views on protoplasm, based partly on a priori grounds and partly on brutal methods of staining and fixation, he investigated simple colloidal solutions. $\mathrm{He}$ established the connexion between electric charge and stability; clearly recognised the globulins as types of "colloidal electrolytes', and went a considerable way towards elucidating the reversible sol-gel transformation. These investigations laid a great part of the foundations of modern colloid science, and the concept of the colloidal electrolyte in particular has been greatly extended by subsequent workers.

In view of the suggested stimulus to these researches, it is interesting to read Hardy's two addresses on "Living Matter", delivered in 1916 and 1928 respectively. In the first of these, parallels between processes in living matter and in 